\title{
Breast Cancer Screening Trends among Lower Income Women of New York: A Time-Series Evaluation of a Population-Based Intervention
}

\author{
Shizhen $\mathrm{He}^{1,2}$ (1), Stephen W. $\operatorname{Pan}^{1}$ (1) \\ ${ }^{1}$ Department of Health and Environmental Sciences, Xi' an Jiaotong-Liverpool University, Suzhou, China \\ ${ }^{2}$ Department of Public Health Sciences, Karolinska Institute, Solna, Sweden
}

\begin{abstract}
Objective: This study aimed to compare the screening rate trends of mammography among New York State's lower-income women and the higherincome women from 1988 to 2010, and evaluate the potential influence of New York State's Breast Cancer Early Detection Program (introduced in 1994) on the mammography use rates of lower-income women.

Materials and Methods: Lower-income women are defined as women aged 40 and over whose household income is lower than $250 \%$ of the single member household federal poverty level (FPL) in the year that they participated in the survey. Higher-income women are defined as women aged 40 and over whose income is greater than $250 \%$ of the five-person household FPL. Data were obtained from the Behavioral Risk Factor Surveillance System. Interrupted time series analysis was conducted to examine screening rates before and after the launch of the Breast Cancer Early Detection program.

Results: Among the lower-income women, the pre-intervention mammography screening rate significantly increased by an average of $15.21 \%$ every two years. However, after implementation of the Breast Cancer Early Detection Program, this rate of increase significantly slowed (slope change=-13.67, $\mathrm{p}=0.00016$ ). The lower-income women and the higher-income women experienced a similar trend change after the intervention started.

Conclusion: This study found limited evidence that the Breast Cancer Early Detection Programme significantly contributed to the state-wide increase in mammography screening rate among lower-income women from 1988 to 2010. Future studies should examine the influence of structural and individual barriers inhibiting uptake of mammography screening among lower-income women.
\end{abstract}

Keywords: Health disparities, socioeconomic, segmented regression, United States

Cite this article as: He S, Pan SW. Breast Cancer Screening Trends among Lower Income Women of New York: A Time-Series Evaluation of a Population-Based Intervention. Eur J Breast Health 2020; 16(4): 255-261.

\section{Introduction}

\section{Background of the problem}

At the population level, breast cancer screening is effective for breast cancer early detection, which can lead to an increase in timely treatment and prolonged life. Mammography, the gold standard of breast cancer screening, can reduce breast cancer mortality and advanced cancer for women over age 40, according to a 2015 meta-analysis (1). However, other meta-analysis has found limited evidence that screening with mammography significantly impacts cancer mortality and that there is a tendency for over-diagnosis and reduced effectiveness (2). Nonetheless, to date, mammography is still considered as a relatively accurate tool for detecting breast cancer (overall sensitivity: $84.4 \%$; specificity: 90.8\%) (3).

In the United States, mammography emerged as an acceptable breast cancer screening approach in the 1960s (4). In the 1970s, mammography had gradually become a common clinical practice but with substantial controversy (4). In the 1980s, because of positive results of a series of randomized controlled trials on mammography, many guidelines began to recommend mammography use, especially among women aged 40 and older (4). Due to the dissemination of mammography screening, mammography use in the United States increased greatly in the 1980s, plateaued through 1993, reached a peak in 1999, subsequently declined slowly during 2000-2004, and stabilized since 2004 (4-6). 
In the United States, mammography is recommended for breast cancer screening by the American Cancer Society, the National Comprehensive Network, and the U.S. Preventive Services Task Force; in contrast, clinical breast exams, another common tool for breast cancer screening, is not recommended by the American Cancer Society or the U.S. Preventive Services Task Force due to limited scientific evidence (7). The American Cancer Society Guidelines recommend that the age of onset for mammography is 40 years old; and the recommended interval between screening procedures is every year for women aged 40-54 and every two years for women aged 55 and older (8). Furthermore, New York State requires insurance (private or public) for breast screening procedures; although mammography is covered through New York's Medicaid program (public insurance) and many private insurance programs, some private health insurance programs in New York State and some government health insurance programs outside New York State may not cover the mammography procedures $(9,10)$.

There is a health disparity of mammography use between lowerincome and higher-income populations. In the United States, among females aged 40 and older who had annual income greater than $>256 \%$ of the 5 -person household federal poverty level (FPL), $82.5 \%$ received a mammogram screening in the last two years. However, among females aged 40 and older who had annual income $<182 \%$ of the 1 -person household FPL, the percentage was only $68.4 \%$ (11). A literature review indicated that low-income women are more likely to be uninsured, leading to lower rates of mammography use (12). Moreover, even after adjusting for race, ethnicity, and insurance status, low-income women are still significantly less likely to have a mammography screening compared with high-income women (13).

In New York State (NYS), breast cancer is the second leading cause of cancer-related death among female, accounting for approximately 2,600 deaths each year $(14,15)$.

Thus, promoting mammography use for low-income women is a health priority in New York State.

\section{Description of the program}

In 1994, New York State Department of Health (NYSDOH) initiated the Breast Cancer Early Detection Program to provide free mammography services to women aged 40 and over, with household incomes at or below $250 \%$ of the federal poverty level (FPL) (10), or who were "financially unable to meet their co-payment or whose insurance did not provide coverage for breast cancer screen-

\section{Key Points}

- Limited evidence was found for that the Breast Cancer Early Detection Programme significantly contributed to the state-wide increase in mammography screening rate among lower-income women from 1988 to 2010 . One explanation could be the low coverage of this program.

- The general trends of mammography use among both low-income and high-income women aged 40 and older in New York State during 1988-2010 were consistent with the national-level trends.

- Misclassification of exposure was the main challenge of this study, in terms of the eligibility for the Breast Cancer Early Detection Programme.

- Future studies should examine the influence of structural and individual barriers inhibiting uptake of mammography screening among lower-income women. ings", in order to increase their access to breast cancer screening (15, p2). Specifically, the Breast Cancer Early Detection Program signed contracts with community-based organizations, who then developed relationships with local healthcare providers (e.g. hospitals, clinics and laboratories) to conduct outreach to provide free cancer screening services for eligible citizens; the Breast Cancer Early Detection Program oversees the delivery of the services and assists the recruitment of eligible clients through hot line referrals (i.e., a phone number that can connect clients to the service nearest them providing free mammography) (15). The outreach also organized state-wide recruitment campaigns to advertise the free mammography services for lower-income women aged 40 and older (15). If breast cancer is found by the screening, these eligible women can participate in the New York State Medicaid Cancer Treatment Program to receive full payment for their treatment (15). Besides the provision of free screening, this program developed and distributed a series of publications on breast cancer screening for health education (15). Theoretically, this program would increase the uptake of mammography screening among lower-income women aged 40 and older.

\section{Rationale and objectives of the study}

This study aimed to illustrate long-term trends in the prevalence of mammography among lower-income women aged 40 and over and to better understand the influence of the Breast Cancer Early Detection Program on the mammography screening rate among lower-income women aged 40 and older in New York State.

To that end, this study aimed to 1 . compare the screening rate trends of mammography among NYS's lower-income women aged 40 and older and the high-income women aged 40 and older from 1988 to 2010 and 2. assess the potential influence of the Breast Cancer Early Detection Program on the mammography use rates of the low-income women aged 40 and older using an interrupted time-series analysis.

\section{Materials and Methods}

\section{Data sources}

The data analysis was based on secondary data from the Behavioral Risk Factor Surveillance System (BRFSS), which is an annual telephone public health survey organized by the Centres for Disease Control (CDC) randomly interviewing community residents aged 18 years and older in each state (16). BRFSS is the largest telephone survey worldwide and has historically been shown to be useful for policy makers to assess public health issues and priorities within states (17). Numerous studies have examined issues regarding the data quality, reliability and validity of the BRFSS, and BRFSS has been considered as a moderately reliable and valid source on within-state estimates for most health-related issues, including data on mammography screening (17-22). A systematic review of reliability and validity studies on BRFSS indicated that the reliability and validity of self-reported mammography screening by phone survey in BRFSS is good after comparison with the National Health Interview Study (face-to-face interview) and mammography registry data (17). The overall BRFSS response rate decreased from approximately $75 \%$ in 1988 to approximately $57 \%$ in 2010 (17).

\section{Study participant eligibility criteria}

The eligibility criteria for the free mammography screening program included women aged 40 and over, with household incomes at or below $250 \%$ of the federal poverty level (FPL) (10), or those who were "financially unable to meet their co-payment or whose 
insurance did not provide coverage for breast cancer screenings" $(15, \mathrm{p} 7)$.

However, as there is no data of insurance coverage in the BRFSS system for the study period, the target group in this study was not based on insurance status.

The target group (lower-income group) in this study was defined as women aged 40 and over whose household income is lower than $250 \%$ of the single member household federal poverty level (FPL) in the year that they participated in the survey (Appendix 1) (23). These criteria were set in order to maximize specificity in determining individuals who were eligible for the program based on income.

The comparison group (higher-income group) was defined as women aged 40 and over whose income is at or over $250 \%$ of the five-person household FPL (Appendix 1). Evidence indicates that the vast majority of individuals in the "higher-income group" would not have been eligible for the Cancer Early Detection program. First, between 1985-2010, over 95\% of United States households had less than five members (24). Hence, no more than $-5 \%$ of individuals in the "higher-income group" would have potentially satisfied the income eligibility criterion of the Cancer Early Detection program. Second, national survey data indicates that of individuals whose household income is at or above $250 \%$ of the five-person household FPL (Appendix 1), only 7.5\% were uninsured (25-33).

Household income between $250 \%$ of the one-person FPL and $250 \%$ of the five-person household FPL was defined as the middleincome group and were not used in this study.

\section{Measures}

As the breast cancer screening question was only asked once every other year during the period of 2002-2010, the time unit used in the analysis was every two years. The following information was extracted from annual surveys (1988-2010) conducted by the BRFSS: state, age group, sex, the household income level of respondents ever had mammogram in last two years. Frequency weighting was performed for all observations in SPSS. Two income groups were derived from the household income level variable: low-income and high-income. Among New York State female respondents aged 40 or older, the proportion of mammography use (in last 2 years) among each income group was calculated.

\section{Data analysis}

Prior to the analysis, an impact model was proposed to hypothesize the impact of the free mammography screening service on increasing the percentage of low-income women aged 40 and older receiving mammography screening. Therefore, a slope change impact model in the percentage of low-income women aged 40 and older receiving mammography screening was assumed.

Interrupted time series analysis was conducted to test the linear slopes of change in the screening rate before (1988-1993) and after the launch of the Breast Cancer Early Detection program (19942010) among the low-income women 40 years and older and highincome women 40 years and older. Evidence of autocorrelation in the full model is limited (Durbin-Watson test statistic: 1.69 (low-income women), 1.70 (high-income women)). The statistical analysis was performed in SPSS version 25 and the level of significance $(\alpha)$ was set at $5 \%$.

\section{Ethics statement}

The current study complies with the research ethics guidelines of Xi'an Jiaotong-Liverpool University. The study was determined not to constitute human subjects research because of the use of anonymous publicly available secondary data and fact that investigators did not have direct contact with respondents.

\section{Results}

The mammography screening rate among the low-income women aged 40 and older significantly increased from $32.0 \%$ in 1988 to $72.4 \%$ in 2010 , increasing by $3.03 \%$ on average every two years (95\% CI 1.59 to $4.46, \mathrm{p}=0.001$ ). In the high-income women aged 40 and older, the breast cancer screening rate significantly increased from $65.1 \%$ in 1988 to $80.3 \%$ in 2010 , increasing by $1.12 \%$ on average every two years (95\% CI 0.29 to 2.06 , p=0.014) (Figure 1). However, it should be noted that both rate trends plateaued after 2000, which might be because of ceiling effects in terms of mammography screening. In addition, Figure 1 shows a trend in opposite directions from 1992 to 1994 between the two groups of women; though the uptake in lower income women continued to increase, there was a decline in uptake by higher income women preceding the launch of the New York State Breast Cancer Early Detection Program.

Among the low-income women aged 40 and older, the pre-intervention mammography screening rate significantly increased by an average of $15.21 \%$ every two years (Table 1 ). However, after implementation of the Breast Cancer Early Detection Programme, this rate of increase significantly slowed (Table 1).

In the high-income women aged 40 and older, the pre-intervention mammography screening rate significantly increased by an average of $5.62 \%$ every two years (Table 1 ). This percentage of increase did not significantly change after implementation of the Breast Cancer Early Detection Programme (Table 1). Though the rate of increase is not statistically significant, the point estimate (-4.98) (Table 1) and the plotted data points (Figure 1) clearly indicate a slowing trend after the intervention. When comparing the low-income women aged 40 and older and the high-income women aged 40 and older, the pre-post intervention slope changes as a percentage of the pre-intervention trend, are remarkably similar between the low- and high-income women $(13.67 / 15.21) \approx(4.98 / 5.62)$ (Table 1).

Table 2 further divided the intervention period into 1994-2000 and 2000-2010, based on the trend in Figure 1. However, even during the first six years of the intervention period (1994 to 2000),

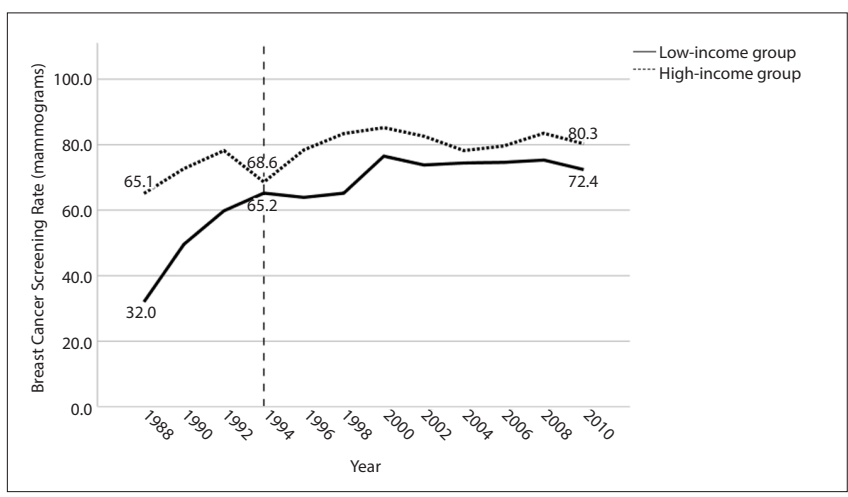

Figure 1. Mammography screening rate among NYS's low-income women aged 40 and older and high-income women aged 40 and older 257 
Table 1. Mammography screening rate trends before and after implementation of the Breast Cancer Early Detection Program

\begin{tabular}{|c|c|c|c|c|}
\hline & Coefficient & $95 \% \mathrm{Cl}$ & t-statistic & $\mathbf{p}$ \\
\hline \multicolumn{5}{|c|}{ Low-income women aged 40 and older (Durbin-Watson test statistic: 1.69) } \\
\hline Intercept & 17.58 & 6.23 to 28.93 & 3.51 & 0.007 \\
\hline Pre-intervention baseline trend & 15.21 & 10.71 to 19.72 & 7.64 & $<0.0001$ \\
\hline Trend change after intervention & -13.668 & -18.66 to -8.67 & -6.19 & 0.00016 \\
\hline \multicolumn{5}{|c|}{ High-income women aged 40 and older (Durbin-Watson test statistic: 1.70) } \\
\hline Intercept & 60.14 & 46.57 to 73.71 & 10.02 & $<0.0001$ \\
\hline Pre-intervention baseline trend & 5.62 & 0.23 to 11.01 & 2.36 & 0.043 \\
\hline Trend change after intervention & -4.98 & -10.96 to 0.99 & -1.89 & 0.092 \\
\hline
\end{tabular}

Table 2. Mammography screening rate trends among low-income women aged 40 and older before and after implementation of the Breast Cancer Early Detection Program (Durbin-Watson test statistic: 2.31)

\begin{tabular}{lcccc} 
& Coefficient & $\mathbf{9 5 \%} \mathbf{C l}$ & t-statistic & P \\
\hline Intercept & 20.12 & 10.86 to 29.39 & 5.01 & 0.001 \\
Pre-intervention baseline rate ratio trend & 13.31 & 9.36 to 17.25 & $<.78$ & -0.0001 \\
Rate trend change after Intervention (1994-2000) & -10.00 & -15.11 to -4.89 & -4.52 & -002 \\
Rate trend change (2000-2010) & -3.12 & -5.89 to -0.03 & -2.63
\end{tabular}

the percentage of increase in screening rate among low-income women aged 40 and older still significantly slowed compared with the pre-intervention period (Table 2), consistent with the plateau trend in Figure 1.

\section{Discussion and Conclusion}

This study compared the screening rate trends of mammography among NYS's lower-income women aged 40 and over and the high-income women aged 40 and over from 1988 to 2010 and assessed the potential influence of the Breast Cancer Early Detection Program on the mammography use rates of the low-income women aged 40 and older using an interrupted time-series analysis based on BRFSS data.

We found that the rate of increase in mammography use among the low-income women aged 40 and older significantly slowed during the intervention period (1994-2010), compared with the pre-intervention period (1988-1994) (Table 1). In addition, the pre-post intervention slope changes as a percentage of the pre-intervention trend, are remarkably similar between the low- and high-income women aged 40 and older $(13.67 / 15.21) \approx(4.98 / 5.62)$. In other words, the low-income women aged 40 and older (very likely to be eligible for the program) and the high-income women aged 40 and older (very unlikely to be eligible for the program) experienced a similar trend change after the intervention started. Therefore, at the state level, the current study did not detect evidence that the Breast Cancer Early Detection Program significantly increased the uptake of mammography screening among the low-income women aged 40 and older.

One explanation for this apparent lack of effect is the low coverage of the Breast Cancer Early Detection Program (50,000 cli- ents per year, 5\% of all 1,000,000 low-income women aged 40 and older). According to New York State Department of Health Cancer Services Program (15), the number of women aged 40-64 eligible for this program (below $250 \%$ of federal poverty line and also uninsured) is about 200,000 per year during 2013-2015. If during 1988-2010, the number of eligible women was also approximately 200,000 per year, then the annual coverage of this program during 2000-2010 would be approximately $25 \%$ $(50,000 / 200,000)$ of all eligible women, which is not high. Indeed, the number of clients receiving free mammography in the Breast Cancer Early Detection Program stopped increasing after 2000. According to New York State Department of Health Cancer Services Program (15, p7), "despite the decreased numbers of women screened by the CSP [Cancer Service Program], estimates of the number of low-income, uninsured women in NYS during the period covered by this report exceeded the capacity of the program". Therefore, the Breast Cancer Early Detection Program may not have enough resources (not specifically indicated, perhaps human resources or financial support) to cover more individuals (15).

\section{Comparison with previous studies}

According to two previous studies (5-6), in the 1980s in the United States, there was a steep increase in the rates of mammography due to the introduction and dissemination period of mammography screening. Mammography use rates in the U.S. plateaued through 1993 , reached a peak in 1999, subsequently declined slowly during 2000-2004 and stabilized since 2004. In the current study, the general trends of mammography use among both low-income and high-income women aged 40 and older in New York State are consistent with the national-level trends. 


\section{Limitations}

One limitation of this study is that the BRFSS data cannot be used to definitively determine which women were and were not eligible for the Breast Cancer Early Detection Program, potentially leading to some misclassification bias. The eligibility criteria for the free mammography screening program included women aged 40 and over, with household incomes below $250 \%$ of the federal poverty level (FPL) (10), or those who were "financially unable to meet their co-payment or whose insurance did not provide coverage for breast cancer screenings" $(15, \mathrm{p} 7)$. However, as the federal poverty line varies by household size, the absence of household size in the BRFSS data precluded us from determining the income eligibility of the women. In order to maximize specificity in determining individuals who were eligible for the program based on income, this study defined the lower-income women based on the household income lower than $250 \%$ of 1 -person household federal poverty line. To some degree this measure may have under-estimated the effects of the program, as some individuals may have had income $>250 \%$ of the 1 -person household FPL, but lower than the multi-person household FPL appropriate to their specific living situation; however, the current measure is the optimal classification using publicly available data.

It is also possible that some women classified as "higher income" may have actually been eligible for the Breast Cancer Early Detection Program. However, by defining the "higher income group" as participants who earned $\geq 250 \%$ the 5-person household FPL, and based on relatively low prevalence of uninsured among this population (7.5\%) (25), members of the "higher income" group were far less likely to have satisfied the eligibility criteria of the Breast Cancer Early Detection Program.

In addition, the nature of the data may limit statistical inferences. The overall BRFSS response rate decreased over time, from approximately $75 \%$ in 1988 to approximately 57\% in $2010(17,34,35)$. Though we cannot attest that the findings are fully free from bias, we content that non-response bias has limited impact on our findings. One study indicated that, for BRFSS data, if response rates are lower than $40 \%$, then the non-response would be associated with under-representation of racial/ethnic minorities and younger individuals (36). Furthermore, CDC and several other studies analysed the influence of low response rates in BRFSS and concluded that the impact of non-response bias is very low for response rates between $30 \%$ and $80 \%(37-40)$.

In addition, the interrupted time series study design may raise concerns about change of time-dependent factors at the individual level (e.g. income level) and unmeasured confounding (such as race, educational attainment, and health conditions). These are the limitations of the interrupted time-series study design, which can be better addressed by randomized controlled trials (RCT) (41). Though RCT studies can provide important evidence, these designs are not possible to be used to retrospectively evaluate public health programs which have already been implemented without randomization or without any proper control, such as the Breast Cancer Early Detection Program. Therefore, given all the available data sources, we contend that the interrupted time series study design is a suitable approach to evaluate this program which was introduced at a population level (i.e. New York State) over a clear implementation period (i.e. 1988-2010) with a clear populationlevel health outcome (i.e. mammography screening rates) (41).

\section{Implications for research and policy}

The decrease in slope in the intervention period compared with the pre-intervention period (Figure 1) needs to be further explored in future studies. Specifically, further studies may aim to identify the specific barriers to mammography screening among low-income women aged 40 and older in New York State and explore to what extent these barriers contribute to the plateaued trends identified by the current study. Furthermore, quantitative studies could be conducted to estimate the number of individuals who do have access to mammography but fail to obtain mammography screening; and after that, qualitative studies might be conducted to explore the major reasons of not obtaining mammography when having access.

For policy makers and program managers, it is important to confirm if finances or shortage of human resources are the major limiting factors preventing more people from participating in the Breast Cancer Early Detection Program. If the limitation is financial, then increased funding for health institutions and health providers offering free mammography services may help improve coverage and uptake of the program among low-income women aged 40 and older. Design of the screening program might also be improved by applying principles of "behavioral economics" for promoting mammography uptake. For example, one principle of "behavioral economics" is that presenting an option as a default choice can increase the possibility it will be chosen (42). One-stop shop screening could be a promising design for the program, whereby by default, patients who fall within the screening criteria (e.g., woman 40 years of age and older) would automatically be scheduled for mammography, unless otherwise indicated by healthcare provider. In other countries (e.g. the United Kingdom and Australia), a systematic review has shown that one-stop shop screening is a costeffective and time-effective way to increase the cancer screening rate, and is acceptable to most patients and general practitioners (43). These same kinds of default mechanisms can also be built into routine general check-ups.

As some women may only screen once and then become less likely to screen again after 2 years (e.g., some women may believe that a single screening is adequate for life), improving adherence to screening schedules could be another important strategy to increase uptake of the program. Risk for overdiagnosis, however, should be noted. According to a meta-analysis on mammography, after adjusting for nonadherence, the magnitude of mortality benefit can increase by about $50 \%$, but risk of overdiagnosis can also increase up to $50 \%$ (44). Therefore, decision aids should be provided to help eligible women weigh the advantages and disadvantages of mammography (44).

In summary, this study found limited evidence that the New York Breast Cancer Early Detection Programme significantly contributed to the state-wide increase in mammography screening rate among low-income women aged 40 and older from 1988 to 2010.

Ethics Committee Approval: According to the Xi'an Jiaotong-Liverpool University Policy on Ethical Conduct in Research, this study is not considered human subjects research. This study only used anonymous, non-identifiable, publicly available secondary data and investigators did not have direct contact with any survey respondents.

\section{Informed Consent: N/A.}

Peer-review: Externally peer-reviewed.

Author Contributions: S.H., and S.W.P., conceptualized the study. S.H., drafted the manuscript. S.H., and S.W.P., provided substantial contribution 259 
to interpretation and revising the manuscript for important intellectual content. S.W.P., provided supervision. Both authors approved the final version of the manuscript to be published and accept accountability for all aspects of the manuscript.

Conflict of Interest: The authors have no conflicts of interest to declare.

Financial Disclosure: The authors declared that this study has received no financial support.

\section{References}

1. Nelson HD, Fu R, Cantor A, Pappas M, Daeges M, Humphrey L. Effectiveness of breast cancer screening: systematic review and meta-analysis to update the 2009 US Preventive Services Task Force recommendation. Ann Intern Med 2016; 164: 244-255. (PMID: 26756588) [Crossref]

2. Gøtzsche PC, Jørgensen KJ. Screening for breast cancer with mammography. Cochrane Database Syst Rev 2013; DOI: 10.1002/14651858. CD001877.pub5 [Crossref]

3. Breast Cancer Surveillance Consortium (BCSC). Performance measures for 1,838,372 screening mammography examinations from 2004 to 2008 by age -- based on BCSC data through 2009. Rockville, MD: National Cancer Institute, 2016. Available from: http://breastscreening.cancer.gov/ data/performance/screening/2009/perf_age.html.

4. National Research Council. Mammography and beyond: developing technologies for the early detection of breast cancer. National Academies Press; 2001 Aug 23.

5. Gangnon RE, Sprague BL, Stout NK, Alagoz O, Weedon-Fekjæ H, Holford TR, Trentham-Dietz A. The contribution of mammography screening to breast cancer incidence trends in the United States: an updated age-period-cohort model. Cancer Epidemiol Biomarkers Prev 2015; 24 : 905-912. (PMID: 25787716) [Crossref]

6. Bleyer A, Welch HG. Effect of three decades of screening mammography on breast-cancer incidence. N Engl J Med 2012; 367: 1998-2005. (PMID: 23171096) [Crossref]

7. Susan G. Komen Breast Cancer Foundation. Breast cancer screening for women at average risk. Bethesda, MD: Susan G. Komen Breast Cancer Foundation, 2018. Available from: https://ww5.komen.org/BreastCancer/GeneralRecommendations.html\#Figure3-1.

8. Oeffinger KC, Fontham ET, Etzioni R, Herzig A, Michaelson JS, Tina Shih YC, Walter LC, Church TR, Flowers CR, LaMonte SJ, Wolf AMD, DeSantis C, Lortet-Tieulent J, Andrews K, Manassaram-Baptiste D, Saslow D, Smith RA, Brawley OW, Wender R, American Cancer Society. Breast cancer screening for women at average risk: 2015 guideline update from the American Cancer Society. JAMA 2015; 314: 1599-1614. (PMID: 26501536) [Crossref]

9. New York State Department of Health (NYSDOH). New York State Breast Cancer Services, Insurance Coverage. New York, NY: New York State Department of Health, 2018. Available from: https://www.ny.gov/ new-york-state-breast-cancer-programs/new-york-state-breast-cancerservices\#nys-cancer-services-program-for-uninsured-individuals.

10. New York State Department of Health (NYSDOH) Cancer Services Program. Breast and Cervical Cancer Early Detection Program Report: Combined Report for Program Years 2005-2006, 2006-2007 and 2007-2008. New York, NY: New York State Department of Health, 2008. Available from: https://www.health.ny.gov/diseases/cancer/cervical/resources/ docs/2005-2008_early_detection_report.pdf.

11. U.S. Centers for Disease Control and Prevention. Morbidity and mortality weekly report (MMWR). Atlanta, GA: U.S. Centers for Disease Control and Prevention. 2005; 54: 981-1012.

12. Peek ME, Han JH. Disparities in screening mammography: current status, interventions, and implications. J Gen Intern Med 2004; 19: 184194. (PMID: 15009798) [Crossref]

13. Katz SJ, Hofer TP. Socioeconomic disparities in preventive care persist despite universal coverage: breast and cervical cancer screening in Ontario and the United States. JAMA 1994; 272: 530-4. (PMID: 8046807) [Crossref]
14. New York State Department of Health (NYSDOH). New York State Breast Cancer Services. New York, NY: New York State Department of Health, 2016. Available from: https://www.ny.gov/new-york-state-breastcancer-programs/new-york-state-breast-cancer-services.

15. New York State Department of Health (NYSDOH) Cancer Services Program. Breast and Cervical Cancer Early Detection Program Report: Combined Report for Program Years 2013-2014 and 2014-2015. New York, NY: New York State Department of Health, 2015. Available from: https://www.health.ny.gov/diseases/cancer/cervical/resources/docs/20132015_cervical_cancer_prevention_report.pdf.

16. Behavioural Risk Factor Surveillance System (BRFSS). BRFSS Frequently Asked Questions (FAQs). Atlanta, GA: U.S. Centers for Disease Control and Prevention, 2017. Available from: https://www.cdc.gov/brfss/about/ brfss_faq.html.

17. Pierannunzi C, Hu S, Balluz L. A systematic review of publications assessing reliability and validity of the Behavioral Risk Factor Surveillance System (BRFSS), 2004-2011. BMC Med Res Methodol 2013; 13: 49. (PMID: 23522349) [Crossref]

18. Hu S, Pierannunzi C, Balluz, L. Integrating a multimode design into a national random-digit-dialed telephone survey. Preventing Chronic Disease 2011; 8: A145.

19. Fahimi M, Link M, Mokdad A, Schwartz DA, Levy P. Tracking chronic disease and risk behavior prevalence as survey participation declines: statistics from the behavioral risk factor surveillance system and other national surveys. Preventing Chronic Disease 2008; 5: A80.

20. Li C, Balluz LS, Ford ES, Okoro CA, Zhao G, Pierannunzi C. A Comparison of Prevalence Estimates for Selected Health Indicators and Chronic Diseases or Conditions from the Behavioral Risk Factor Surveillance System, the National Health Interview Survey, and the National Health and Nutrition Examination Survey, 2007-2008. Prev Med 2012; 54: 381387. (PMID: 22521996) [Crossref]

21. Nelson DE, Powell-Griner E, Town M, Kovar MG. A comparison of national estimates from the National Health Interview Survey and the Behavioral Risk Factor Surveillance System. Am J Public Health 2003; 93: 1335-1341. (PMID: 12893624) [Crossref]

22. Mokdad AH, Stroup DF, Giles WH. Public health surveillance for behavioral risk factors in a changing environment: recommendations from the Behavioral Risk Factor Surveillance team. MMWR, 2003; 52 (RR-9):112.

23. U.S. Department of Health \& Human Services. Prior HHS Poverty Guidelines and Federal Register References. Washington, DC: U.S. Department of Health \& Human Services, 2018. Available from: https://aspe.hhs.gov/ prior-hhs-poverty-guidelines-and-federal-register-references.

24. U.S. Census Bureau. Households by Size: 1960 to Present. Washington, DC: U.S. Census Bureau, 2017. Available from: https://www.census.gov/ data/tables/time-series/demo/families/households.html.

25. U.S. Census Bureau. Current Population Reports: Health Insurance Coverage in the United States: 2013. Washington, DC: U.S. Census Bureau, 2003. Available from: https://www.nber.org/cps/hi/2014redesign/p60250.pdf.

26. U.S. Census Bureau. Income, Poverty, and Health Insurance Coverage in the United States: 2009. Washington, DC: U.S. Census Bureau, 2010. Available from: https://usa.usembassy.de/etexts/soc/healthins2002.pdf.

27. Ross JS, Bradley EH, Busch SH. Use of health care services by lowerincome and higher-income uninsured adults. JAMA 2006; 295: 20272036. (PMID: 16670411) [Crossref]

28. U.S. Census Bureau. Income, Poverty, and Health Insurance Coverage in the United States: 2004. Washington, DC: U.S. Census Bureau, 2005. Available from: https://www.census.gov/prod/2005pubs/p60229.pdf

29. U.S. Census Bureau. Health Insurance Coverage: 2002. Washington, DC: U.S. Census Bureau, 2003. Available from: https://usa.usembassy. de/etexts/soc/healthins2002.pdf.

30. U.S. Census Bureau. Health Insurance Coverage: 1999. Washington, DC: U.S. Census Bureau, 2000. Available from: https://www.census.gov/ prod/2000pubs/p60-211.pdf. 
31. U.S. Census Bureau. Health Insurance Coverage: 1997. Washington, DC: U.S. Census Bureau, 1998. Available from: https://www2.census. gov/prod2/popscan/p60-202.pdf.

32. U.S. Census Bureau. Health Insurance Coverage: 1995. Washington, DC: U.S. Census Bureau, 1996. Available from: https://www.census.gov/ prod/2/pop/p60/p60-195.pdf.

33. U.S. Census Bureau. Health Insurance Coverage: 1993. Washington, DC: U.S. Census Bureau, 1994. Available from: https://www.census.gov/ prod/1/statbrief/sb94_28.pdf.

34. Rolle-Lake L, Robbins E. Behavioral Risk Factor Surveillance System (BRFSS): 2020. Available from: https://www.ncbi.nlm.nih.gov/books/ NBK553031/

35. Fahimi M, Link M, Mokdad A, Schwartz DA, Levy P. Tracking chronic disease and risk behavior prevalence as survey participation declines: statistics from the behavioral risk factor surveillance system and other national surveys. Prev Chronic Dis. 2008;5(3):A80.

36. Schneider KL, Clark MA, Rakowski W, Lapane KL. Evaluating the impact of non-response bias in the Behavioral Risk Factor Surveillance System (BRFSS). J Epidemiol Community Health 2012; 66: 290-295. (PMID: 20961872) [Crossref]

37. Washington State Department of Health. Health of Washington State Report - Appendix B: Primary Data Sources. Washington, Olympia: Washington State Department of Health, 2013. Available from: https://www. doh.wa.gov/Portals/1/Documents/1500/AppB.pdf
38. Groves RM, Peytcheva E. The impact of nonresponse rates on nonresponse bias. Public Opin Q 2008; 72: 167-189. [Crossref]

39. Groves RM. Nonresponse rates and nonresponse bias in household surveys. Public Opin Q 2006; 70: 646-675. [Crossref]

40. Keeter S, Kennedy C, Dimock M, Best J, Craighill P. Gauging the impact of growing nonresponse on estimates from a national RDD telephone survey. Public Opin Q 2006; 70: 759-779. [Crossref]

41. Bernal JL, Cummins S, Gasparrini A. Interrupted time series regression for the evaluation of public health interventions: a tutorial. Int J Epidemiol 2017; 46: 348-355. (PMID: 27283160) [Crossref]

42. Marteau TM, Ogilvie D, Roland M, Suhrcke M, Kelly MP. Judging nudging: can nudging improve population health? BMJ 2011; 342: d228. (PMID: 21266441) [Crossref]

43. Friedemann Smith C, Tompson A, Holtman GA, Bankhead C, Gleeson F, Lasserson D, Nicholson BD. General practitioner referrals to one-stop clinics for symptoms that could be indicative of cancer: a systematic review of use and clinical outcomes. Fam Pract 2019; 36: 255-261. (PMID: 30052877) [Crossref]

44. Jacklyn G, Glasziou P, Macaskill P, Barratt A. Meta-analysis of breast cancer mortality benefit and overdiagnosis adjusted for adherence: improving information on the effects of attending screening mammography. Br J Cancer 2016; 114: 1269-1276. (PMID: 27124337) [Crossref] 


\section{Appendix 1. Federal poverty level (FPL) between 1987 and 2010 (17)}

\begin{tabular}{|c|c|c|c|c|}
\hline Year & $\begin{array}{l}\text { Federal poverty level } \\
\text { (FPL) for 1-person } \\
\text { households }\end{array}$ & $\begin{array}{l}250 \% \text { of } 1 \text {-person } \\
\text { household FPL }\end{array}$ & $\begin{array}{l}\text { Federal poverty level } \\
\text { (FPL) for 5-person } \\
\text { households }\end{array}$ & $\begin{array}{l}250 \% \text { of } 5 \text {-person } \\
\text { household FPL }\end{array}$ \\
\hline 1987 & 5,500 & 13750 & 13100 & 32750 \\
\hline 1988 & 5,770 & 14425 & 13610 & 34025 \\
\hline 1989 & 5,980 & 14950 & 14140 & 35350 \\
\hline 1990 & 6,280 & 15700 & 14840 & 37100 \\
\hline 1991 & 6,620 & 16550 & 15660 & 39150 \\
\hline 1992 & 6,810 & 17025 & 16330 & 40825 \\
\hline 1993 & 6,970 & 17425 & 16810 & 42025 \\
\hline 1994 & 7,360 & 18400 & 17280 & 43200 \\
\hline 1995 & 7,470 & 18675 & 17710 & 44275 \\
\hline 1996 & 7,740 & 19350 & 18220 & 45550 \\
\hline 1997 & 7,890 & 19725 & 18770 & 46925 \\
\hline 1998 & 8,050 & 20125 & 19250 & 48125 \\
\hline 1999 & 8,240 & 20600 & 19520 & 48800 \\
\hline 2000 & 8,350 & 20875 & 19950 & 49875 \\
\hline 2001 & 8,590 & 21475 & 20670 & 51675 \\
\hline 2002 & 8,860 & 22150 & 21180 & 52950 \\
\hline 2003 & 8,980 & 22450 & 21540 & 53850 \\
\hline 2004 & 9,310 & 23275 & 22030 & 55075 \\
\hline 2005 & 9,570 & 23925 & 22610 & 56525 \\
\hline 2006 & 9,800 & 24500 & 23400 & 58500 \\
\hline 2007 & 10,210 & 25525 & 24130 & 60325 \\
\hline 2008 & 10,400 & 26000 & 24800 & 62000 \\
\hline 2009 & 10,830 & 27075 & 25790 & 64475 \\
\hline 2010 & 10,830 & 27075 & 25790 & 64475 \\
\hline 2016 & 11770 & 29425 & 28410 & 71025 \\
\hline
\end{tabular}

